\title{
Note
}

\section{Longevity and Mortality of Boreal Woodland Caribou (Rangifer tarandus caribou) of the Dehcho Region, Northwest Territories}

\author{
Nicholas C. LARTER ${ }^{1,2}$ and DanNy G. Allaire ${ }^{1}$ \\ ${ }^{1}$ Department of Environment and Natural Resources, Government of the Northwest Territories, P.O. Box 240, Fort Simpson, \\ Northwest Territories X0E 0N0 Canada \\ ${ }^{2}$ Corresponding author: nic_larter@gov.nt.ca
}

Larter, Nicholas C., and Danny G. Allaire. 2016. Longevity and mortality of boreal Woodland Caribou (Rangifer tarandus caribou) of the Dehcho region, Northwest Territories. Canadian Field-Naturalist 130(3): 222-223.

As part of an ongoing study of the ecology of boreal Woodland Caribou (Rangifer tarandus caribou), we investigated death sites of collared caribou to collect biological samples and determine a cause of death. The teeth collected from 25 adult females that had died since being radio collared were aged by cementum analysis. The age at death for one caribou was 22 years; this was only the second caribou tooth among 42776 aged at a commercial laboratory found to be that old. An additional six of the 25 caribou were 13-17 years old at time of death. All but one of these seven female caribou had calved at least once during the period they were radio collared and monitored.

Key Words: Woodland Caribou; Rangifer tarandus caribou; Dehcho region; old age; cementum aging; Northwest Territories

As part of an ongoing study of the ecology of boreal Woodland Caribou (Rangifer tarandus caribou), female caribou have been captured and outfitted with satellite or Global Positioning System (GPS) radio collars since 2004. Collars deployed since 2005 have been outfitted with programmable mechanisms that release after four or five calving seasons. The movements and fate of collared females are monitored to estimate adult female survival, calf production, recruitment, and annual rate of population increase (Larter and Allaire 2015).

When collared animals die, we attempt to investigate as soon as possible to determine cause of death and collect teeth to establish an accurate age for the animal. However, our study area extends over some $80000 \mathrm{~km}^{2}$ of remote boreal forest in the Dehcho region of the southwestern Northwest Territories (Figure 1), which makes accessing death sites logistically challenging. Of the 67 deaths to date, 53 have been successfully investigated. Once we arrive at a death site, we attempt to collect any teeth associated with the caribou remains. We have located teeth at 25 of the $53(47 \%)$ sites visited. These teeth were forwarded to a commercial laboratory (Matson's Laboratory, Manhatten, Montana) where they were aged by cementum age analysis (Matson 1981; Matson's Laboratory n.d.).

The caribou population of the Dehcho is subject to natural predation and subsistence harvest. Gray Wolves (Canis lupus), American Black Bears (Ursus americanus), Wolverines (Gulo gulo), and Canadian Lynx (Lynx canadensis) are potential predators. Wolf predation is suspected in the deaths of 41 collared caribou (61\%), and American Black Bear predation is suspected in the death of one collared caribou (1\%) in our study. Six of the 67 collared caribou (9\%) that died were harvested. Every year, most female caribou in the study have successfully calved; the mean estimated annual female survival rate has been about 0.8 . Low levels of common parasites and exposure to common diseases are not considered to be of significant concern (Johnson et al. 2010) to Woodland Caribou in this area; however, recently, evidence has been found of exposure to the bacterium Erysipelothrix rhusiopathiae, which has been implicated in caribou mortalities in northern British Columbia.

Of the 25 dead caribou for which we have recovered teeth, seven were 13 years or older, with the oldest aged 22 years. Based on mean adult female survival rate in this study, liberally, fewer than $1 \%$ of adult females in the population should reach 22 years. As of August 2016, 45014 caribou teeth from North America have been aged by Matson's Laboratory, and only one other animal has been aged at 22 years: a caribou from Alaska, aged in 1989 (C. Nistler and G. Matson, personal communication). Wolf predation is the suspected cause of death for all seven long-lived caribou, possibly with old age being a factor. These seven animals were captured throughout the study area, two in the same group, and all but one had at least one calf during their final years.

What is significant about the oldest caribou is that she was captured and collared 27 months before her death, i.e., she was collared longer than any of the other long-lived caribou. She successfully bore calves at age 20 and 21 years, on 17 May 2013 and 16 May 2014 , respectively. The calf born in 2013 did not survive to the following March but the calf born in 2014 did survive to March 2015. We were unable to determine whether the adult calved at 22 years. 


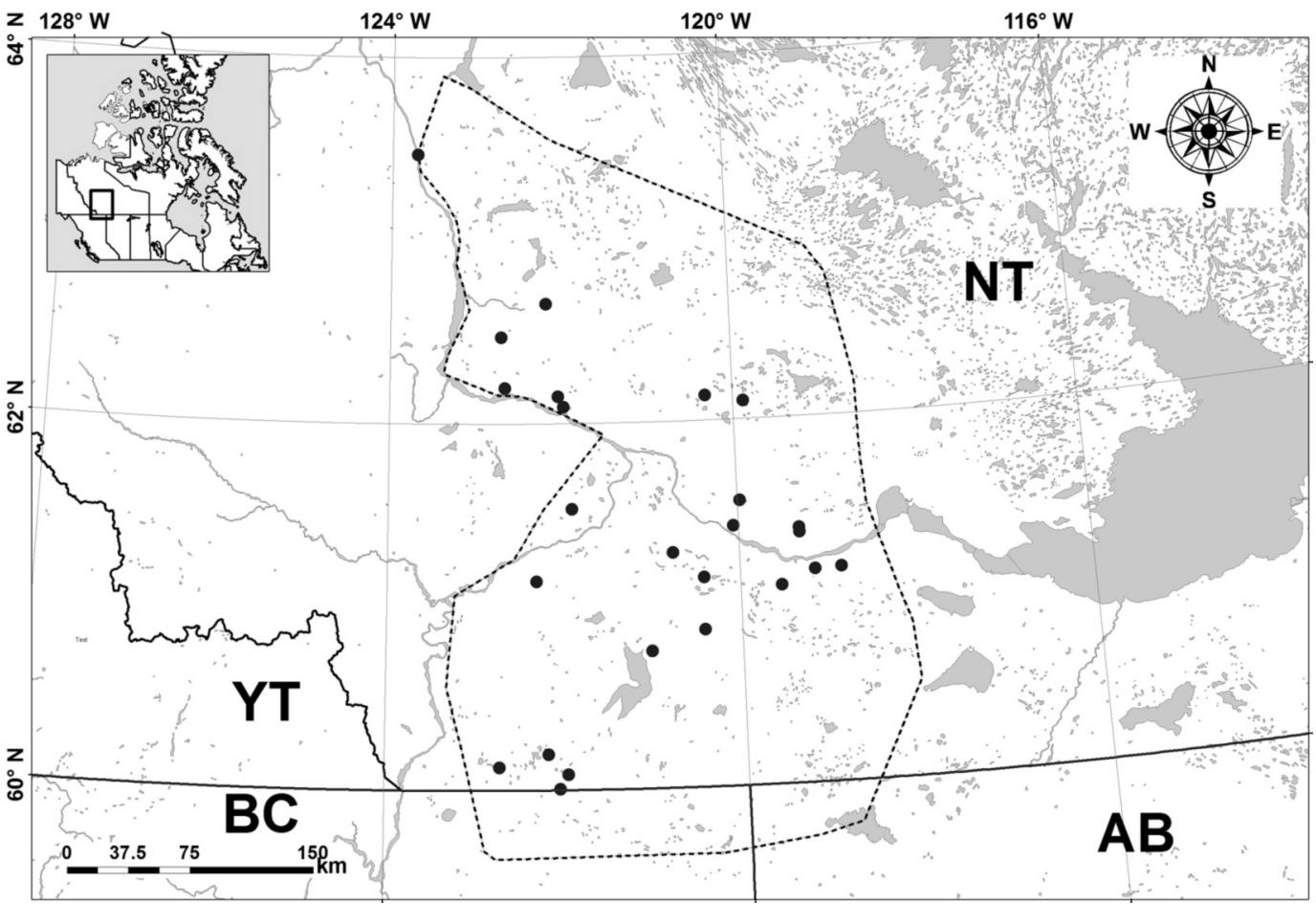

FIGURE 1. The area where collared boreal Woodland Caribou (Rangifer tarandus caribou) were located during this study. The 25 death sites where teeth were recovered are indicated with black dots $(\bullet)$. Note: $\mathrm{AB}=$ Alberta, $\mathrm{BC}=\mathrm{British}$ Columbia, $\mathrm{NT}=$ Northwest Territories, YT $=$ Yukon.

We would expect fewer caribou to become pregnant and bear calves as they age. Yet, all of the longlived caribou that we could monitor during a calving period had calves. This implies a high pregnancy rate throughout their lifetime. A population with long-lived females that maintain high productivity would produce more calves over their lifetime, and the population would have more resilience to disturbance and change.

\section{Acknowledgements}

We thank the Dehcho Boreal Caribou Working Group and our First Nation partners for their continued support of the Dehcho Boreal Caribou Study. We thank Diversified Environmental Services for capturing and deploying collars on caribou. Matson's Laboratory aged all teeth. C. Nistler and G. Matson provided archived caribou age records. We thank the helicopter pilots and Environment and Natural Resources staff members who assisted in visiting death sites and retrieving teeth. B. Elkin and T. Jung commented on earlier drafts of this article. Funding for this project came from the Northwest Territories Western Biophysical
Program, Cumulative Impacts Monitoring Program, Environment Canada, and the Department of Environment and Natural Resources.

\section{Literature Cited}

Johnson, D., N. J. Harms, N. C. Larter, B. T. Elkin, H. Tabel, and G. Wei. 2010. Serum biochemistry, serology and parasitology of boreal caribou (Rangifer tarandus caribou) in the Northwest Territories, Canada. Journal of Wildlife Diseases 46: 1096-1107.

Larter, N. C., and D. G. Allaire. 2015. Dehcho boreal caribou study progress report, April 2015. Environment and Natural Resources, Fort Simpson, Northwest Territories, Canada. Accessed 17 March 2016. http://www.enr.gov.nt.ca /sites/default/files/progrep11_dehcho_boreal_caribou_study 2015.pdf.

Matson, G. M. 1981. Workbook for Cementum Analysis. Matson's, Milltown, Montana, USA.

Matson's Lab. n.d. Aging experience, accuracy and precision. Matson's Laboratory, Manhattan, Montana, USA. Accessed 15 March 2016. http://matsonslab.com/the-science/aging -experience-accuracy-and-precision/.

Received 30 April 2016

Accepted 9 August 2016 